\title{
COMMENTARY
}

\section{Endocrinology: the next 60 years}

\author{
Waljit S Dhillo, Kevin G Murphy and Steve Bloom \\ Department of Metabolic Medicine, Imperial College London, Hammersmith Hospital, 6th Floor Commonwealth Building, Du Cane Road, \\ London W12 ONN, UK \\ (Requests for offprints should be addressed to S Bloom; Email: s.bloom@imperial.ac.uk)
}

\begin{abstract}
The next 60 years promise to arouse the interest of scientists and clinicians while challenging the central dogmas of endocrine physiology. In this review we consider the fundamental changes in the understanding of endocrine physiology that have taken place in recent years and the new hormones discovered. We discuss how the brain is emerging as an important regulator of endocrine and neuroendocrine
\end{abstract}

circuits. Advances in molecular biology techniques and the use of genomics and other -omics in furthering our understanding of endocrine physiology are also discussed. Finally, we propose that in 2066 we may prescribe designer hormones to healthy subjects.

Journal of Endocrinology (2006) 190, 7-10

\section{Introduction}

The tremendous advances in endocrinology (i.e. the study of regulation through internal secretions) seen in the last 60 years have revealed profound insufficiencies in the classical endocrine models. Endocrinology is now known to comprise a multitude of diverse signalling systems besides the classical hypothalamo-pituitary regulation of peripheral endocrine organ function. A century after Bayliss and Starling coined the term 'hormone' following their discovery of secretin, new hormones continue to be discovered. The next 60 years promise to arouse the interest of scientists and clinicians, while challenging the central dogmas of endocrine physiology. Although the future of the field is impossible to predict, contemporary research offers valuable clues to the state of endocrinology in 2066.

\section{The next 60 years}

The endocrine text books will be re-written

It is now well recognised that endocrine cells do not, as previously believed, release only a single hormone, that hormones can bind to a number of different receptors and receptors can bind to a number of different hormones. New research is challenging many other long-held beliefs in endocrinology. The categorisation of the differing modes of action of peptide/protein hormones and steroid hormones has been revealed as awkward and artificial. Recent studies now suggest that many of the rapid actions of steroid hormones may be mediated via non-genomic pathways, which remain to be fully elucidated (Bassett et al. 2003). The serum-binding proteins, to which many circulating hormones bind, have long been believed to be the simple storage and transport reservoirs for the biologically active unbound hormones. However, it is now thought that binding proteins play more dynamic roles. Sex hormone-binding globulin, for example, appears to be crucial to the transport of testosterone across the cell membrane, and hence its biological actions (Hammes et al. 2005). Although insulin-like growth factor (IGF) is 'stored' on binding proteins, the release of the active protein is regulated by locally released tissue-specific enzymes. Thus, IGF has different actions in different tissues. Hormone systems appear to be linked to cues such as metabolic sensors, which respond to both the intracellular and extracellular environment (Kahn et al. 2005). The distinct boundaries of endocrinology itself are blurring as the overlaps between endocrine, paracrine and neurocrine signalling systems become more apparent (Toni 2004). Who knows which tenets of the endocrinological canon will fall next?

New endocrine organs and hormones will be discovered

Until recently, most hormones were discovered and characterised by functional assays following their extraction from specific tissues. For example, the discovery of 
corticotrophin-releasing hormone in 1981 required over 3000 ovine hypothalami (Vale et al. 1981). Reverse pharmacology has revolutionised this process. The conserved sequence of G-protein coupled receptors (GPCRs) has permitted the discovery and cloning of thousands of these receptors. Reverse pharmacology uses libraries of cells expressing these orphan GPCRs to screen putative ligands for receptor binding and activation. Potential peptidergic ligands can be predicted by their genetic sequence, and known molecules efficiently assessed for previously unknown cell-signalling functions. Reverse pharmacology has led to the discovery of a number of important hormones, including the 'hunger hormone' ghrelin and the reproductive hormone kisspeptin (Kojima et al. 1999, Seminara et al. 2003). Such technology has demonstrated how disparate categories of molecules are able to act as hormones. Molecules previously thought to act only as substrates for, or by-products of, various metabolic processes, such as fatty acids, amino acids and nitric oxide, or originally characterised in quite different roles, such as bile acids, are now known to act as bioactive cell-to-cell signalling molecules. New discoveries have increased the complexity of endocrine axes previously considered well described. For example, the discovery of thyrostimulin (Nakabayashi et al. 2002) and a role for the endogenous T3 derivative, 3-iodothyronamine, in mediating the non-genomic actions of the thyroid hormones via a GPCR, have led to a re-evaluation of the hypothalamopituitary-thyroid axis (Scanlan et al. 2004). The putative nongenomic actions of a number of steroid hormones suggest that they or their derivatives may activate as yet undetermined cell surface receptors. The human genome project has found that humans have approximately 20 000-25 000 genes; around the same number as the mouse and barely more than Caenorhabditis elegans. Much of the complexity of higher mammals may be due to post-translational modifications. This appears to be true for endocrine systems; one gene codes for multiple signalling peptides or proteins. For example, the proopiomelanocortin gene codes for a precursor molecule which is tissue specifically processed into adrenocorticotrophin in the anterior pituitary and $\boldsymbol{\alpha}$-melanocyte stimulating hormone in the arcuate nucleus. The ghrelin gene has recently been discovered to code for another peptide hormone called obestatin, which appears to have functionally antagonistic effects to ghrelin (Zhang et al. 2005). Future studies are likely to reveal the importance of post-translational regulatory mechanisms in modulating numerous endocrine functions.

Our view of endocrine organs has also become more complicated. In addition to the classical endocrine organs, the heart, liver and lungs are now known to have important endocrine functions. Organs once thought to be metabolically inert, such as adipose tissue, the vascular endothelium or the skin, are now considered active endocrine organs. For example, adipose tissue secretes a number of signalling proteins called adipokines. Over 50 adipokines have been described to date, including leptin, resistin and adiponectin, which are thought to be involved in the physiological regulation of energy homeostasis (Koerner et al. 2005). Adipokine research may lead to therapies for obesity and diabetes. In addition, the roles of known endocrine organs have expanded. For example, although the diffuse endocrine system has long been known to secrete hormones required for normal gut function, more recently it has been shown that gastro-intestinal hormones influence the central circuits regulating hunger and body weight (Dhillo \& Bloom 2004).

In the next few decades, we are likely to discover that most, if not all, organs have some endocrine function, employing known hormones in novel scenarios, molecules with previously characterised functions in novel endocrine roles, and unknown hormones discovered using techniques such as reverse pharmacology.

\section{The conceptual barrier between the brain and the periphery will become more permeable}

The brain is known to regulate several endocrine systems via the secretion of hypothalamic hormones that influence pituitary secretion. However, the brain is also emerging as an important regulator of other endocrine and neuroendocrine circuits. For example, although glucose homeostasis was once thought to be primarily regulated by the peripheral glucose sensing of the pancreatic islets and the subsequent regulation of insulin and glucagon release, it is now known that the brain plays a vital role in sensing and manipulating peripheral glucose concentrations (Porte et al. 1975, Horvath et al. 2004, Levin et al. 2004). The brain is also known to respond to peripheral signals of energy stores, such as the adipose hormone leptin, and food intake, such as the gut hormone peptide YY 3-36. Such signals do not only stimulate or inhibit neuronal firing in the hypothalamic arcuate nucleus to regulate energy intake (Badman \& Flier 2005). They can also rapidly rewire these neurones, altering their response to subsequent hormonal inputs and, in the case of ghrelin, affect functions such as memory (Pinto et al. 2004, Diano et al. 2006). In addition, neural connections between the central nervous system and adipose deposits suggest that the brain may directly regulate lipolysis (Kreier et al. 2006). Thus, the concept of the brain as a black box separate from the peripheral organs is being replaced by a more integrative model in which the brain directly influences and is influenced by peripheral endocrine function. Future research may reveal direct central regulation of other endocrine functions, and uncover the extent of neuronal plasticity in response to a number of hormones.

\section{New molecular biology techniques will make impossible experiments possible}

The last two decades have seen advances in molecular biology that have greatly aided the discovery of the physiological functions of hormone/receptor systems. The generation of multiple animal models with deletion of individual genes throughout the body has provided vital information on the 
physiological role of hormones, including recently kisspeptin, for example. Knockout of the kisspeptin receptor, GPR54, causes hypogonadotrophic hypogonadism (Seminara et al. 2003). Kisspeptin is now known to be one of the most powerful stimulants of luteinising hormone release in animals (Dungan et al. 2006) and humans (Dhillo et al. 2005), and may be a novel treatment for infertility. However, such 'knockout' models have been limited by their inability to differentiate between developmental and adult physiological roles, or to investigate tissue-specific functions. More sophisticated molecular biology techniques are now being used to knockout genes in specific sites in adult animals. For example, although developmental compensation means the neuropeptide $\mathrm{Y}$ (NPY) and agouti-related protein (AgRP) double knockout animals have a normal body weight, the thin phenotype observed following the postnatal ablation of the NPY/AgRP neurone in the hypothalamic arcuate nucleus clearly demonstrates the importance of this neurone in energy homeostasis (Flier 2006). Brain region-specific ablation of the leptin receptor has been used to try to tease apart the circuits responsible for governing its various effects (Cohen et al. 2001, Dhillon et al. 2006). The future seems likely to bring more such models.

New tools have also revolutionised genomics, the quantitative study of genes and their regulatory sequences. The use of microchip arrays can identify genes involved in response to a physiological stimulus and discover novel disease-associated genes. Following genomics have come transcriptomics (RNA and gene expression), proteomics (protein expression), metabolomics (metabolites and metabolic networks), glycomics (glycobiology-focused proteomics), lipidomics (non-water-soluble metabolites) pharmacogenomics (the quantitative study on how genetics affects hosts' response to drugs) and physiomics (physiological dynamics and functions of whole organisms). Although we currently lack the tools to comprehensively and efficiently investigate these subsequent -omics, the increased emphasis on a system-wide, integrative approach to biology seems certain to drive further technological innovation in these areas.

\section{We will prescribe designer hormones to healthy patients}

The next 60 years will see a revolution in clinical endocrinology. The clinical utility of hormone-based drugs has previously been limited to replacement of absent hormones in endocrine disease, and the use of drugs such as somatostatin to inhibit hormone release in acromegaly and neuroendocrine tumours. Genomic profiling of patients may lead to specific treatments being determined by genotype. New drugs exploiting the actions of the diffuse endocrine system are already being designed. Byetta (Amylin Pharmaceuticals and Eli Lilly, USA), a drug based upon the hormone glucagon-like peptide-1, is now licensed to improve glycaemic control in type II diabetes, and also promotes weight loss. Other weight-control drugs based on gut hormones are in the development pipeline, and ghrelin may be clinically useful to stimulate appetite and food intake in various anorectic patient groups (Neary et al. 2004, Wynne et al. 2005). In the future, characterisation of receptor subtypes or tissue-specific glycoprotein motifs may allow us to design hormone analogues with tissue-specific effects (Fig. 1). Such drugs would stimulate only the specific actions desired, without unwanted side effects. Healthy humans of the future may take pills based on anabolic steroids to lay down muscle before an important football match, ghrelin mimetics to improve their memory for an exam, gut hormones to lose

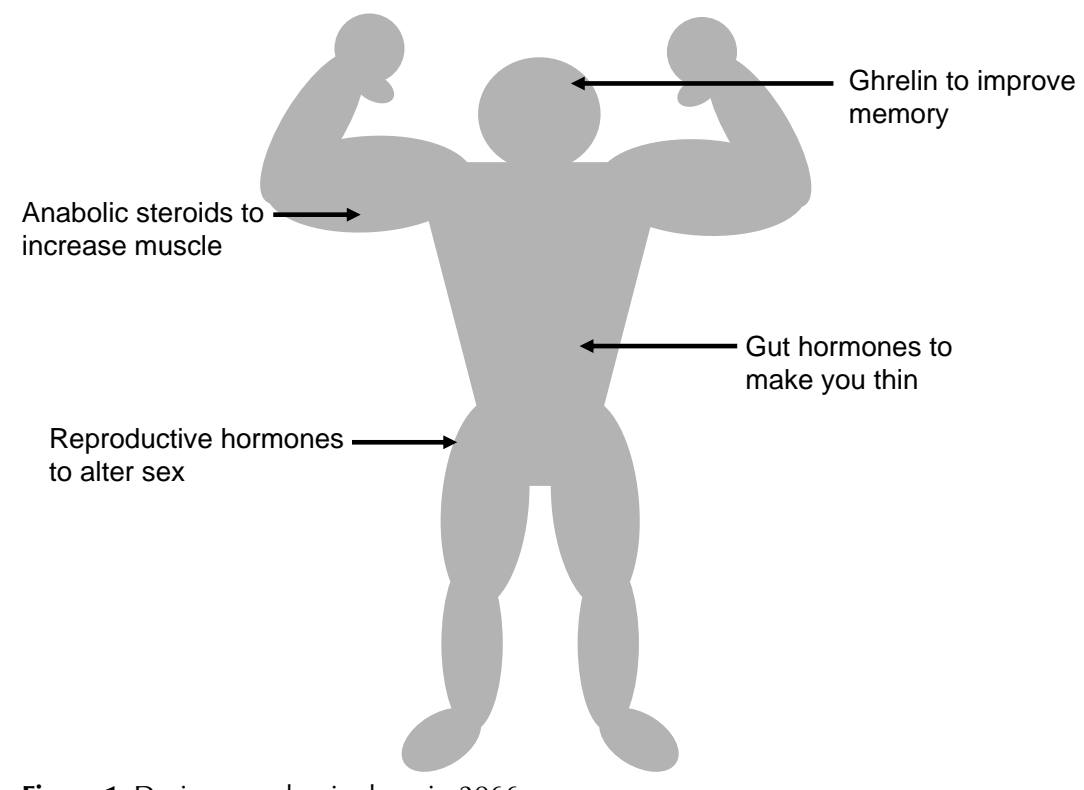

Figure 1 Designer endocrinology in 2066. 
the fat they accumulated over Christmas and reproductive hormone derivatives to change their gender for their summer holidays as a refreshing change.

\section{Acknowledgements}

WSD is funded by a Department of Health Clinician Scientist Fellowship. KGM is funded by a BBSRC New Investigator Award. The authors declare that there is no conflict of interest that would prejudice the impartiality of this scientific work.

\section{References}

Badman MK \& Flier JS 2005 The gut and energy balance: visceral allies in the obesity wars. Science 307 1909-1914.

Bassett JH, Harvey CB \& Williams GR 2003 Mechanisms of thyroid hormone receptor-specific nuclear and extra nuclear actions. Molecular Cell Endocrinology 213 1-11.

Cohen P, Zhao C, Cai X, Montez JM, Rohani SC, Feinstein P, Mombaerts P \& Friedman JM 2001 Selective deletion of leptin receptor in neurons leads to obesity. Journal of Clinical Investigation 108 1113-1121.

Dhillo WS \& Bloom SR 2004 Gastrointestinal hormones and regulation of food intake. Hormone and Metabolic Research 36 846-851.

Dhillo WS, Chaudhri OB, Patterson M, Thompson EL, Murphy KG, Badman MK, McGowan BM, Amber V, Patel S, Ghatei MA et al. 2005 Kisspeptin-54 stimulates the hypothalamic-pituitary-gonadal axis in human males. Journal of Clinical Endocrinology and Metabolism 90 6609-6615.

Dhillon H, Zigman JM, Ye C, Lee CE, McGovern RA, Tang V, Kenny CD, Christiansen LM, White RD, Edelstein EA et al. 2006 Leptin directly activates SF1 neurons in the VMH, and this action by leptin is required for normal body-weight homeostasis. Neuron 49 191-203.

Diano S, Farr SA, Benoit SC, McNay EC, da Silva I, Horvath B, Gaskin FS, Nonaka N, Jaeger LB, Banks WA et al. 2006 Ghrelin controls hippocampal spine synapse density and memory performance. Nature Neuroscience 9 381-388.

Dungan HM, Clifton DK \& Steiner RA 2006 Minireview: kisspeptin neurons as central processors in the regulation of gonadotropin-releasing hormone secretion. Endocrinology 147 1154-1158.

Flier JS 2006 AgRP in energy balance: will the real AgRP please stand up? Cell Metabolism 3 83-85.

Hammes A, Andreassen TK, Spoelgen R, Raila J, Hubner N, Schulz H, Metzger J, Schweigert FJ, Luppa PB, Nykjaer A et al. 2005 Role of endocytosis in cellular uptake of sex steroids. Cell 122 751-762.

Horvath TL, Diano S \& Tschop M 2004 Brain circuits regulating energy homeostasis. Neuroscientist 10 235-246.

Kahn BB, Alquier T, Carling D \& Hardie DG 2005 AMP-activated protein kinase: ancient energy gauge provides clues to modern understanding of metabolism. Cell Metabolism 1 15-25.

Koerner A, Kratzsch J \& Kiess W 2005 Adipocytokines: leptin-the classical, resistin-the controversical, adiponectin-the promising, and more to come. Best Practice and Research Clinical Endocrinology and Metabolism 19 525-546.
Kojima M, Hosoda H, Date Y, Nakazato M, Matsuo H \& Kangawa K 1999 Ghrelin is a growth-hormone-releasing acylated peptide from stomach. Nature 402 656-660.

Kreier F, Kap YS, Mettenleiter TC, van Heijningen C, van der Vliet J, Kalsbeek A, Sauerwein HP, Fliers E, Romijn JA \& Buijs RM 2006 Tracing from fat tissue, liver, and pancreas: a neuroanatomical framework for the role of the brain in type 2 diabetes. Endocrinology 147 1140-1147.

Levin BE, Routh VH, Kang L, Sanders NM \& Dunn-Meynell AA 2004 Neuronal glucosensing: what do we know after 50 years? Diabetes $\mathbf{5 3} 2521-2528$.

Nakabayashi K, Matsumi H, Bhalla A, Bae J, Mosselman S, Hsu SY \& Hsueh AJ 2002 Thyrostimulin, a heterodimer of two new human glycoprotein hormone subunits, activates the thyroid-stimulating hormone receptor. Journal of Clinical Investigation 109 1445-1452.

Neary NM, Small CJ, Wren AM, Lee JL, Druce MR, Palmieri C, Frost GS, Ghatei MA, Coombes RC \& Bloom SR 2004 Ghrelin increases energy intake in cancer patients with impaired appetite: acute, randomized, placebo-controlled trial. Journal of Clinical Endocrinology and Metabolism $892832-2836$.

Pinto S, Roseberry AG, Liu H, Diano S, Shanabrough M, Cai X, Friedman JM \& Horvath TL 2004 Rapid rewiring of arcuate nucleus feeding circuits by leptin. Science 304 110-115.

Porte D Jr, Woods SC, Chen M, Smith PH \& Ensinck JW 1975 Central factors in the control of insulin and glucagon secretion. Pharmacology Biochemistry and Behavior 3 127-133.

Scanlan TS, Suchland KL, Hart ME, Chiellini G, Huang Y, Kruzich PJ, Frascarelli S, Crossley DA, Bunzow JR, Ronca-Testoni S et al. 2004 3-Iodothyronamine is an endogenous and rapid-acting derivative of thyroid hormone. Nature Medicine 10 638-642.

Seminara SB, Messager S, Chatzidaki EE, Thresher RR, Acierno JS Jr, Shagoury JK, Bo-Abbas Y, Kuohung W, Schwinof KM, Hendrick AG et al. 2003 The GPR54 gene as a regulator of puberty. New England Journal of Medicine 349 1614-1627.

Toni R 2004 The neuroendocrine system: organization and homeostatic role. Journal of Endocrinology Investment 27(Suppl 6) 35-47.

Vale W, Spiess J, Rivier C \& Rivier J 1981 Characterization of a 41-residue ovine hypothalamic peptide that stimulates secretion of corticotropin and beta-endorphin. Science 213 1394-1397.

Wynne K, Giannitsopoulou K, Small CJ, Patterson M, Frost G, Ghatei MA, Brown EA, Bloom SR \& Choi P 2005 Subcutaneous ghrelin enhances acute food intake in malnourished patients who receive maintenance peritoneal dialysis: a randomized, placebo-controlled trial. Journal of the American Society of Nephrology 16 2111-2118.

Zhang JV, Ren PG, Vsian-Kretchmer O, Luo CW, Rauch R, Klein C \& Hsueh AJ 2005 Obestatin, a peptide encoded by the ghrelin gene, opposes ghrelin's effects on food intake. Science 310 996-999.

Received 13 March 2006

Accepted 24 April 2006

Made available online as an Accepted Preprint

3 May 2006 